\title{
An Investigation into the Geometric Parameters Affecting Field Uniformity in Four Pole Magnetisers
}

\author{
James Borg Bartolo ${ }^{1}$, Piotr Klimczyk ${ }^{2}$, Kai Tiwisina ${ }^{2}$, Patrick Denke ${ }^{2}$, Stefan Siebert ${ }^{2}$, Christopher Gerada ${ }^{1}$ \\ ${ }^{1}$ University of Nottingham, NG72RD Nottingham UK, \\ ${ }^{2}$ Dr. Brockhaus Messstechnik GmbH \& Co. KG, D-58507 Lüdenscheid Germany \\ (eexjb4@nottingham.ac.uk)
}

\begin{abstract}
In recent years, the field-metric method for measuring the joule losses set up in an electrical steel laminate when subjected to a rotating field has gained popularity. The ideal geometry of the magnetiser required to set up such a field is still however the subject of much debate. The work presented in this paper aims at providing some useful guidelines which might be considered when undertaking the construction of the simplest of such magnetizing setups having four salient poles excited by a two phase system and using a square sample. A 3D model for this rotational power loss tester was simulated for different pole geometries with the induction uniformity being assessed for every alteration.
\end{abstract}

\section{Introduction}

In a bid to reduce cost and weight, the demand for high speed, high power density electrical machines operating at high levels of efficiency has over the past decade seen an unprecedented increase. To enable such an increase in power density an increase in both fundamental supply frequency and current loading is often required. This coupled with novel stator/winding geometries expose the constituent magnetic materials of the machine to harmonic rich excitation frequencies at high field intensity values.

The design of the required cooling regimes for such novel designs is closely linked to the correct estimation of the incurred iron losses due to both spatially pulsating and rotating fields. A general consensus on the measurement of pulsating/ alternating losses in electrical steel has led to standards such as the IEC 60404 being widely adopted. Unfortunately this is not the case for the measuring of iron losses due to spatially rotating fields. A number of methods have been proposed for the job, [1], [2] with a limited agreement being achieved on the reported loss values, as reported in [3].

Over the past years the field-metric approach, based on the Poynting's theorem description of the rotational loss problem, as given in [4], has gained preference. A number of different magnetiser geometries, [5], [6], were described as possible solutions to achieve induction uniformity. The simplicity in design of the two-phase fourpole geometry, however, allows for high precision in manufacturing and sample location.

The work presented in this paper is based on such a commercially available two-phase, four-pole test setup and aims at providing an insight into the affects of various pole geometries on the induction, level and quality, within the test sample. Such work aims to contribute to knowledge already presented in $[5,7,8]$ by further investigating the affect of the introduction of a pole side taper, and magnetiser assembly imperfections such as pole-yoke air gaps. The presented conclusions are based on an induction uniformity analysis performed on field maps obtained via 3D finite element simulations.

\section{Model geometry and simulation setup}

To cater for the affects of pole tapering, pole-yoke air gaps and the proper location of the sample plane (x-y) with respect to the pole tip, in the $\mathrm{z}$ dimension, a 3D model of the magnetising yoke was setup as shown in Figure1(a) with the salient pole parameters shown in Figures.1.(b, c, d) for different projections. The optimal dimensions for the pole taper ' $\vartheta_{n}$ ', tip height ' $\mathrm{TH}$ ' and sample size were discussed in [8],[5] and empirically deduced via a number of built tester iterates. In this study, such parameters are therefore considered as constant as detailed in Figure 1 and Table 1. The varied dimensions are detailed section 4 along with the results obtained for the figures of merit, (section 3), obtained for each case.

Due to computational requirements and for the purpose of such geometric optimisation it was considered sufficient to analyse the field maps, $\mathrm{B}(\mathrm{x}, \mathrm{y}, \mathrm{z})$, taken from the centre plane, of the sample for 1 time instant, using a 3D finite element solver, at this stage the variation in field distribution along the sample's depth was not evaluated. The sample material was modelled as isotropic with a non-linear BH curve, typical for M330-35A material. The sample's conductivity was set at $2 \times 10^{5} \mathrm{~S} / \mathrm{m}$. The laminate nature of the magnetiser poles was also considered by using a non-linear anisotropic material with different $\mathrm{BH}$ curves and conductivities for the planes lying parallel and normal to the laminate stack directions. The conductivity within the laminate plane was $2 \times 10^{5} \mathrm{~S} / \mathrm{m}$ whilst that normal to such plane was $1 \times 10^{3} \mathrm{~S} / \mathrm{m}$. The whole model employed a tetrahedral mesh 
system having 273100 nodes and a liner interpolating function was used to evaluate field quantities at required sampling points. In the results which follow, coil 2 (ref. Figure 1) is energised inducing a flux along the $\mathrm{x}$-axis.

Table 1

Investigated variations in Pole Geometry, note cases 5 and 7 use the original dimension set

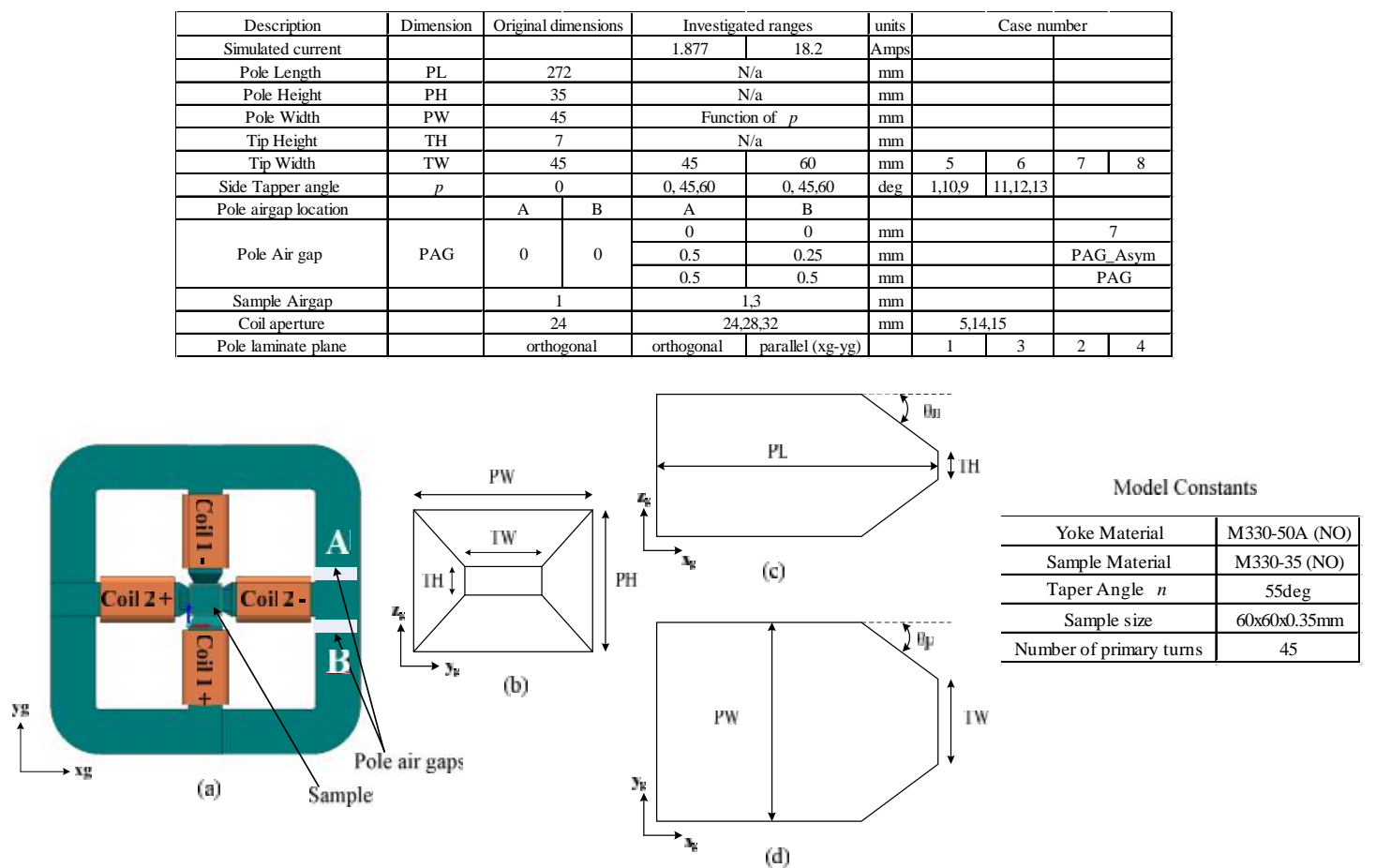

Figure 1 Magnetising yoke geometry in full plan view including the introduction of the parasitic air gaps at the pole-yoke interface (a).frontal projection of a pole tip (b), side elevation of a pole tip (c) and plan view of a pole tip (d).

\section{Criteria for assessing induction uniformity}

The proposed variations to the pole geometry were assessed on the basis of their affect on the induction uniformity within the sample. Such uniformity was assessed globally, using a rate of change criterion, whilst locally; the deviation of edge and corner induction values from the sample's mean induction value, evaluated in the area enclosed by the measuring coils, was employed.

\subsection{The mean rate-of-change criterion}

Using the coordinate system defined in Figure 2, and considering the condition, in which only coil 2 is energised, the flux density variation brought about by the flux traversing the sample in the $y_{\mathrm{g}}-\mathrm{z}_{\mathrm{g}}$ plane is of interest. The resulting spatial variation in induction magnitude at the centre plane coordinate $\mathrm{z}_{\text {mid }},|\mathrm{B}|\left(\mathrm{x}, \mathrm{y}, \mathrm{z}_{\mathrm{mid}}\right)$, was extracted using a smoothing function into a square matrix, $\mathbf{B}[i, j]$. This matrix, obtained by discretizing the sample space using $\mathbf{n} \times \mathbf{m}$ points, would have its column vectors $\mathbf{B}_{\mathbf{x}}$, of size [n $\left.\mathbf{x} 1\right]$, represent the field variation along the discretised $\mathrm{x}$-axis, $\mathrm{x}_{\mathrm{g}}[i]$ and row vectors $\mathbf{B}_{\mathbf{y}}$, of size $[1 \mathrm{x} \mathbf{m}]$, represent the field variation along the discretised $\mathrm{y}$-axis $\mathrm{y}_{\mathrm{g}}[j]$ of the sample, for $i=1,2, \ldots \boldsymbol{n}$, and $j=1,2, \ldots \boldsymbol{m}$.

To evaluate uniformity in the resulting discrete spatial domain, the finite difference between the $\mathbf{B}_{\mathbf{y}}$ values (difference along the $\mathrm{y}_{\mathrm{g}}$ direction) at each discrete volume defined by the increment in the $\mathrm{x}$-direction $\mathrm{x}_{\mathrm{g}}[i]$, must be evaluated. The more uniform the distribution of $\mathbf{B}$ within the particular $y_{\mathrm{g}}-\mathrm{z}_{\mathrm{g}}$ plane of interest; the smaller the finite difference values obtained with respect to $y_{g}$. A difference matrix is thus formed having $\mathbf{n}$ row vectors each with index, $i$, representing the finite difference vectors at each location $\mathrm{x}_{\mathrm{g}}[i]$. This concept is illustrated in Figure 3 , in which the finite-difference variations along the $\mathrm{y}_{\mathrm{g}}[j]$-dimension at two $\mathrm{x}_{\mathrm{g}}[i]$ locations, $i=1$, (flux entry point) and $i=10$ (at $6 \mathrm{~mm}$ within the sample) are shown, for a 100 point discretisation of the coordinate space.

The mean of each of the formed difference row vectors is then evaluated at each position $\mathrm{x}_{\mathrm{g}}[i]$ and used a criterion of uniformity at that particular discrete location along the x-axis. This vector of means has size [nx1] and can be expressed using the forward, centred and backward finite difference terms by equation (1). 


$$
\overline{\Delta B_{y}}[i]=\frac{1}{m}\left[\frac{B[i, 2]-B[i, 1]}{\Delta y}+\sum_{j=2}^{m-1} \frac{B[i, j+1]-B[i, j-1]}{2 \Delta y}+\frac{B[i, m]-B[i, m-1]}{\Delta y}\right] \quad i=1,2, \ldots n ; j=1,2, \ldots m
$$

Where: $i$ denotes the index along the column vector whilst $j$ is the index along the row vector.
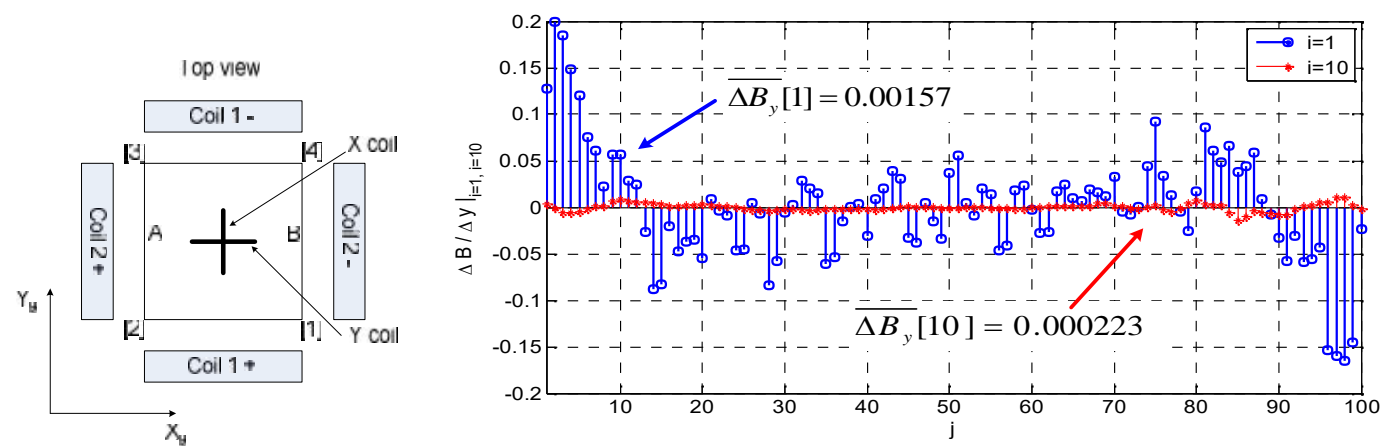

Figure 2 (a) Reference system used, (b) Variation of finite differences against sample number along the $\mathrm{y}_{\mathrm{g}}$ direction

Thus in order to obtain a figure of merit which expresses the field uniformity across the whole sample, the mean of the vector expressed in equation (1) was evaluated and denoted by, $M_{B y x}$.

Evaluating this mean will give an indication of how the induction parallel to the excited yoke tip, (in this case parallel to the y-direction, will vary as one moves from one pole to the next. The magnitude of such a mean and resulting standard deviation, are therefore used as the primary criteria to assess the field uniformity in the sample. Smaller values for both figures of merit reflect a more uniform field.

\subsection{The Induction deviation criteria}

The resulting deviation from the mean sample induction at the sample edges and corners (as defined in Figure.2) was used as a metric for the comparison of local field uniformity. The mean sample induction value was evaluated over the area enclosed by the measuring coils at the centre of the sample. The deviation at the sample's edge was computed using the first and last row vectors of the induction matrix as expressed in equation $(2 b)$.

$$
\varepsilon_{r c}=\frac{\mathbf{B}[i, j]-B_{c a}}{B_{c a}} ; \quad i=1, n ; j=1, m^{(2 \mathrm{a})} \varepsilon_{e}=\frac{\mathbf{B}_{\mathbf{y}}[i]-B_{c a}}{B_{c a}} ; \quad i=1, n{ }^{(2 \mathrm{~b})} \varepsilon_{m}(x, y)=\frac{\mathbf{B}[i, j]-B_{c a}}{B_{c a}} ; \quad i=1, . . n ; j=1, \ldots m^{(2 \mathrm{c})}
$$

Where: $\varepsilon_{\mathrm{rc}}$ is the deviation at the sample corners, $\varepsilon_{\mathrm{e}}$ is the deviation at the sample edges, $\mathrm{B}[i, j]$ is the induction matrix, $\mathbf{B}_{\mathrm{y}}[i]$ is the induction matrix and $\mathrm{B}_{\mathrm{ca}}$ is the induction level averaged over the coil aperture area. The resulting deviation or 'error' surface is also computed, $\varepsilon_{\mathrm{m}}(\mathrm{x}, \mathrm{y})$, for each case, illustrating the spatial deviation in the measured induction magnitude at a given location when compared to the sample's mean induction.

\section{Results}

The spatial mean-rate-of-change index $\mathrm{M}_{\mathrm{Byx}}$ for the investigated cases along with induction deviation at the edges and corners is tabulated in Tables $2 \mathrm{a}$,b. The resulting error surfaces showing the differences between the saturated and unsaturated cases pole tip affects and the inclusion of pole air gaps are given in Figures 3 to 5 .

Table $2 \mathrm{a}$

\begin{tabular}{|c|c|c|c|c|c|c|c|c|c|c|c|c|c|c|c|c|c|}
\hline \multirow[t]{2}{*}{$\begin{array}{c}\text { Case } \\
\text { number }\end{array}$} & \multirow[t]{2}{*}{$\begin{array}{c}\text { Laminate } \\
\text { orientation }\end{array}$} & \multirow[t]{2}{*}{ Tip width } & \multirow[t]{2}{*}{ Side taper } & \multirow[t]{2}{*}{$\begin{array}{c}\text { Coil } \\
\text { aperture }\end{array}$} & \multirow[t]{2}{*}{$\begin{array}{l}\text { Sample } \\
\text { air-gap }\end{array}$} & \multicolumn{2}{|c|}{ Pole air-gaps } & \multirow[t]{2}{*}{$\begin{array}{c}\text { Excitation } \\
\text { current }\end{array}$} & \multirow[t]{2}{*}{$\mathrm{B}_{\mathrm{ca}}$} & \multirow[t]{2}{*}{$\left|\mathrm{M}_{\mathrm{Byx}}\right|$} & \multirow[t]{2}{*}{$\begin{array}{l}\text { Standard } \\
\text { Deviation } \\
\text { for } \mathrm{M}_{\mathrm{Byx}}\end{array}$} & \multirow{2}{*}{\begin{tabular}{|c}
$\begin{array}{c}\text { Deviation } \\
\text { at sample } \\
\text { Edge A }\end{array}$ \\
$\varepsilon_{\mathrm{e}}$ \\
\end{tabular}} & \multirow{2}{*}{\begin{tabular}{|c}
$\mid \begin{array}{c}\text { Deviation } \\
\text { at sample } \\
\text { Edge B }\end{array}$ \\
$\varepsilon_{\mathrm{e}}$ \\
\end{tabular}} & \multicolumn{4}{|c|}{ Deviation at the sample corners $\varepsilon_{\mathrm{rc}}$} \\
\hline & & & & & & A & B & & & & & & & 1 & 2 & 3 & 4 \\
\hline & & $\mathrm{mm}$ & Deg & $\mathrm{mm}$ & $\mathrm{mm}$ & $\mathrm{mm}$ & $\mathrm{mm}$ & Amps & Tesla & & & & & & & & \\
\hline 1 & Orthogonal & 45 & 0 & 24 & 3 & 0 & 0 & 1.877 & 0.82351 & $9.06 \mathrm{E}-06$ & \begin{tabular}{|c|}
$9.17 \mathrm{E}-05$ \\
\end{tabular} & -0.5331 & -0.5364 & -0.6006 & -0.6165 & -0.5952 & -0.6286 \\
\hline 2 & \begin{tabular}{|l|} 
Parallel \\
\end{tabular} & 45 & 0 & 24 & 3 & 0 & 0 & 1.877 & 0.83557 & $6.63 \mathrm{E}-06$ & $9.74 \mathrm{E}-05$ & -0.5329 & -0.5351 & -0.5999 & -0.6152 & -0.5942 & -0.6261 \\
\hline 3 & Orthogonal & 45 & 0 & 24 & 3 & 0 & 0 & 18.2 & 1.7557 & $1.36 \mathrm{E}-05$ & 0.000175 & -0.0687 & -0.0689 & -0.1130 & -0.1325 & -0.1366 & -0.1412 \\
\hline 4 & \begin{tabular}{|c|} 
Parallel \\
\end{tabular} & 45 & 0 & 24 & 3 & 0 & 0 & 18.2 & 1.7585 & $1.40 \mathrm{E}-05$ & \begin{tabular}{|l|}
0.000176 \\
\end{tabular} & -0.0682 & -0.0685 & -0.1117 & -0.1310 & -0.1355 & -0.1399 \\
\hline
\end{tabular}

Summary of the obtained results 
Table $2 b$

Summary of obtained results

\begin{tabular}{|c|c|c|c|c|c|c|c|c|c|c|c|c|c|c|c|c|c|}
\hline \multirow[t]{2}{*}{$\begin{array}{c}\text { Case } \\
\text { number }\end{array}$} & \multirow[t]{2}{*}{$\begin{array}{l}\text { Laminate } \\
\text { orientation }\end{array}$} & \multirow[t]{2}{*}{ Tip width } & \multirow[t]{2}{*}{ Side taper } & \multirow[t]{2}{*}{\begin{tabular}{|c|} 
Coil \\
aperture
\end{tabular}} & \multirow[t]{2}{*}{$\begin{array}{l}\text { Sample } \\
\text { air-gap }\end{array}$} & \multicolumn{2}{|c|}{ Pole air-gaps } & \multirow[t]{2}{*}{$\begin{array}{c}\text { Excitation } \\
\text { current }\end{array}$} & \multirow[t]{2}{*}{$\mathrm{B}_{\mathrm{ca}}$} & \multirow[t]{2}{*}{$\left|\mathrm{M}_{\mathrm{Byx}}\right|$} & \multirow[t]{2}{*}{$\begin{array}{c}\text { Standard } \\
\text { Deviation } \\
\text { for } \mathrm{M}_{\mathrm{Byx}}\end{array}$} & \multirow{2}{*}{\begin{tabular}{|c}
$\begin{array}{c}\text { Deviation } \\
\text { at sample } \\
\text { Edge A }\end{array}$ \\
$\varepsilon_{\mathrm{e}}$ \\
\end{tabular}} & \multirow{2}{*}{\begin{tabular}{|c|c}
$\begin{array}{c}\text { Deviation } \\
\text { at sample } \\
\text { Edge B }\end{array}$ \\
$\varepsilon_{\mathrm{e}}$ \\
\end{tabular}} & \multicolumn{4}{|c|}{ Deviation at the sample corners $\varepsilon_{\mathrm{rc}}$} \\
\hline & & & & & & $\mathrm{A}$ & $\mathrm{B}$ & & & & & & & 1 & 2 & 3 & 4 \\
\hline & & $\mathrm{mm}$ & Deg & $\mathrm{mm}$ & $\mathrm{mm}$ & $\mathrm{mm}$ & $\mathrm{mm}$ & Amps & Tesla & & & & & & & & \\
\hline 5 & Orthogonal & 45 & 0 & 24 & 1 & 0 & 0 & 1.877 & 1.2283 & $9.07 \mathrm{E}-06$ & 0.000217 & -0.3538 & -0.3631 & -0.7116 & -0.6890 & -0.7110 & -0.6915 \\
\hline 6 & Orthogonal & 60 & 0 & 24 & 1 & 0 & 0 & 1.877 & 1.2249 & $5.5 \mathrm{E}-05$ & 0.000393 & -0.5154 & -0.5131 & -0.2725 & -0.1376 & -0.0836 & -0.1404 \\
\hline 7 & Orthogonal & 45 & 0 & 24 & 1 & 0 & 0 & 18.2 & 1.7756 & $2.15 \mathrm{E}-05$ & 0.000255 & -0.0513 & -0.0460 & -0.2196 & -0.2399 & -0.2079 & -0.1977 \\
\hline 8 & Orthogonal & 60 & 0 & 24 & 1 & 0 & 0 & 18.2 & 1.7775 & $8.33 \mathrm{E}-06$ & 0.000282 & -0.0554 & -0.0469 & 0.1452 & 0.1523 & 0.1485 & 0.1437 \\
\hline & & & & & & & & & & & & & & & & & \\
\hline 1 & Orthogonal & 45 & 0 & 24 & 3 & 0 & 0 & 1.877 & 0.82351 & $9.06 \mathrm{E}-06$ & $9.17 \mathrm{E}-05$ & -0.5331 & -0.5364 & -0.6006 & -0.6165 & -0.5952 & -0.6286 \\
\hline 9 & Orthogonal & 45 & 60 & 24 & 3 & 0 & 0 & 1.877 & 0.82864 & $1.43 \mathrm{E}-05$ & 0.000102 & -0.5362 & -0.5371 & -0.5745 & -0.5838 & -0.5645 & -0.6063 \\
\hline 10 & Orthogonal & 45 & 45 & 24 & 3 & 0 & 0 & 1.877 & 0.82668 & $2.64 \mathrm{E}-06$ & 0.000105 & -0.5313 & -0.5371 & -0.5535 & -0.5624 & -0.5443 & -0.5940 \\
\hline 11 & Orthogonal & 60 & 0 & 24 & 3 & 0 & 0 & 1.877 & 0.86037 & $1.09 \mathrm{E}-06$ & $9.53 \mathrm{E}-05$ & -0.5189 & -0.5225 & -0.4190 & -0.3976 & -0.4144 & -0.4773 \\
\hline 12 & Orthogonal & 60 & 60 & 24 & 3 & 0 & 0 & 1.877 & 0.85311 & $1.11 \mathrm{E}-05$ & 0.000123 & -0.5154 & -0.5230 & -0.4105 & -0.3944 & -0.4276 & -0.4629 \\
\hline 13 & Orthogonal & 60 & 45 & 24 & 3 & 0 & 0 & 1.877 & 0.83566 & $2.57 \mathrm{E}-05$ & 0.000142 & -0.5163 & -0.5246 & -0.4156 & -0.3520 & -0.4033 & -0.4632 \\
\hline & & & & & & & & & & & & & & & & & \\
\hline $5^{*}$ & Orthogonal & 45 & 0 & 24 & 1 & 0 & 0 & 1.877 & 1.2283 & $2.44 \mathrm{E}-03$ & 0.000217 & -0.3538 & -0.3631 & -0.7116 & -0.6890 & -0.7110 & -0.6915 \\
\hline $14^{*}$ & Orthogonal & 45 & 0 & 28 & 1 & 0 & 0 & 1.877 & 1.1549 & $2.02 \mathrm{E}-03$ & 0.000159 & -0.5005 & -0.5017 & -0.7155 & -0.7346 & -0.7310 & -0.7295 \\
\hline $15^{*}$ & Orthogonal & 45 & 0 & 32 & 1 & 0 & 0 & 1.877 & 1.1557 & $1.69 \mathrm{E}-03$ & \begin{tabular}{|l|}
0.000161 \\
\end{tabular} & -0.5063 & -0.5023 & -0.7161 & -0.7347 & -0.7299 & -0.7297 \\
\hline 7 & Orthogonal & 45 & 0 & 24 & 1 & 0 & 0 & 18.2 & 1.7756 & $2.15 \mathrm{E}-05$ & 0.000255 & -0.0513 & -0.0460 & -0.2196 & -0.2399 & -0.2079 & -0.1977 \\
\hline PAG & \begin{tabular}{|l|} 
Parallel \\
\end{tabular} & 45 & 0 & 24 & 1 & 0.5 & 0.5 & 18.2 & 1.7776 & $5.30 \mathrm{E}-05$ & 0.000382 & -0.0406 & -0.0452 & -0.2102 & -0.2340 & -0.1684 & -0.2144 \\
\hline PAG_asym & Parallel & 45 & 0 & 24 & 1 & 0.5 & 0.25 & 18.2 & 1.7782 & $4.82 \mathrm{E}-05$ & 0.000365 & -0.0404 & -0.0455 & -0.2082 & -0.2343 & -0.1631 & -0.2174 \\
\hline
\end{tabular}

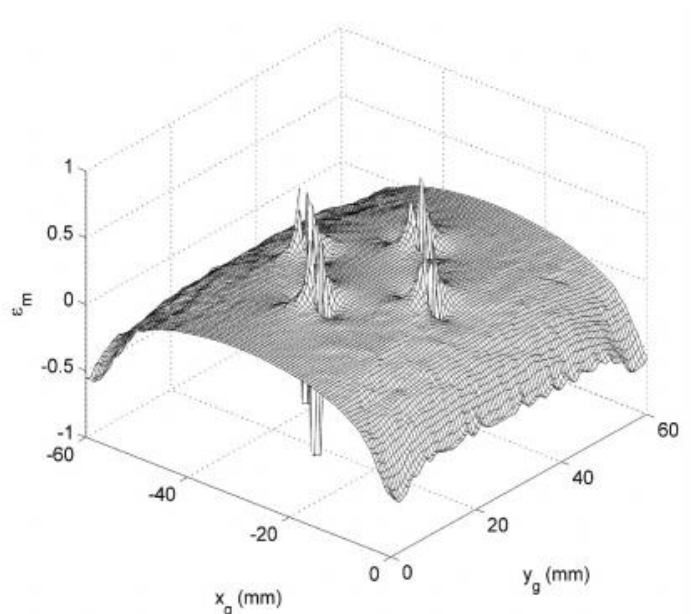

(a)

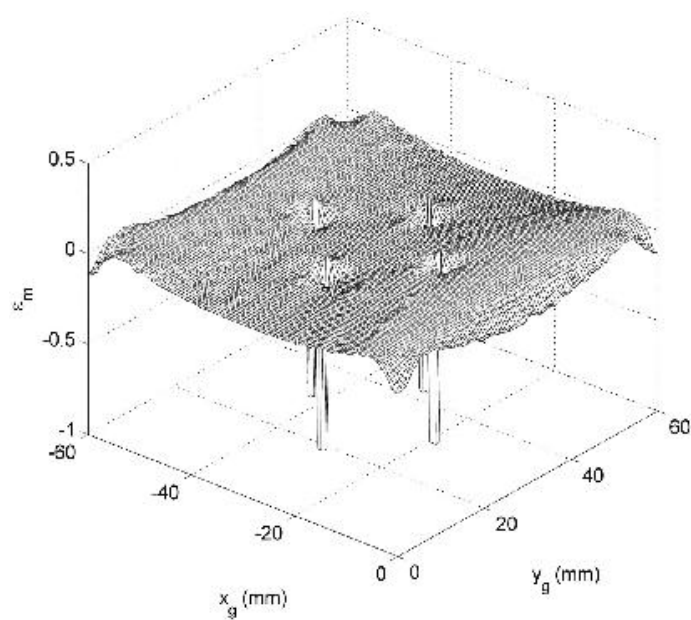

(b)

Figure 3 Surface plot showing the deviation in sample induction from the mean value, (a) for case 1 with pole laminates orthogonal to the sample plane and $\mathrm{B}_{\mathrm{ca}}=0.82 \mathrm{~T}$, (b) case 3 with pole laminates orthogonal to the sample plane and $\mathrm{B}_{\mathrm{ca}}=1.75 \mathrm{~T}$

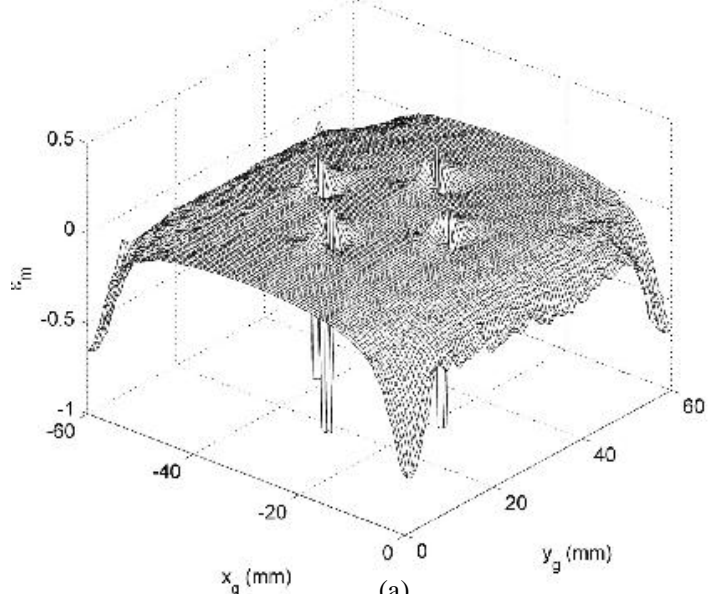

(a)

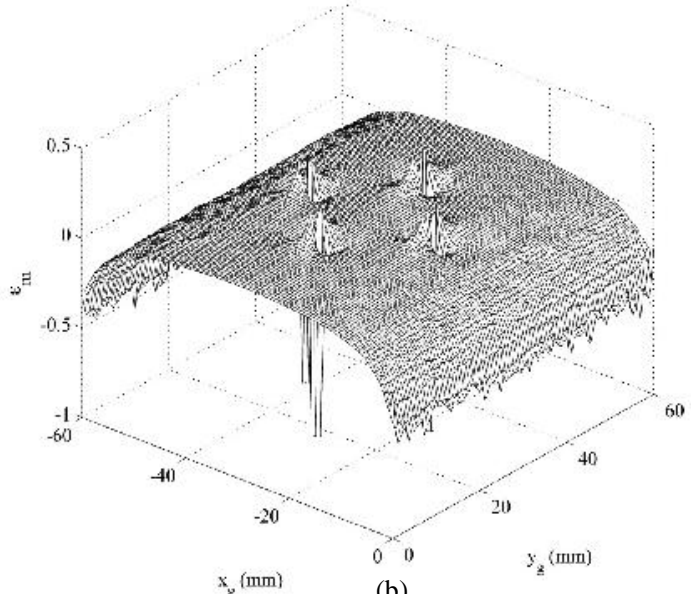

(b)

Figure 4 Surface plot showing the deviation in sample induction from the mean value for, (a) case 5 with tip width at $45 \mathrm{~mm}$ and $\mathrm{B}_{\mathrm{ca}}=1.23 \mathrm{~T}$, (b) case 6 with tip width equal to sample width and $\mathrm{B}_{\mathrm{ca}}=1.22 \mathrm{~T}$ 


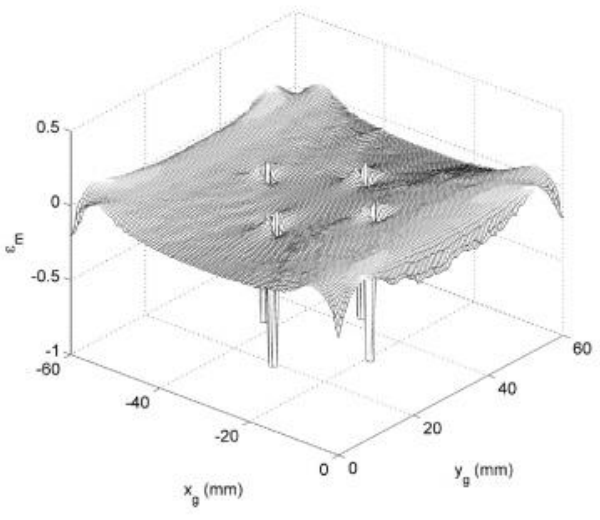

(a)

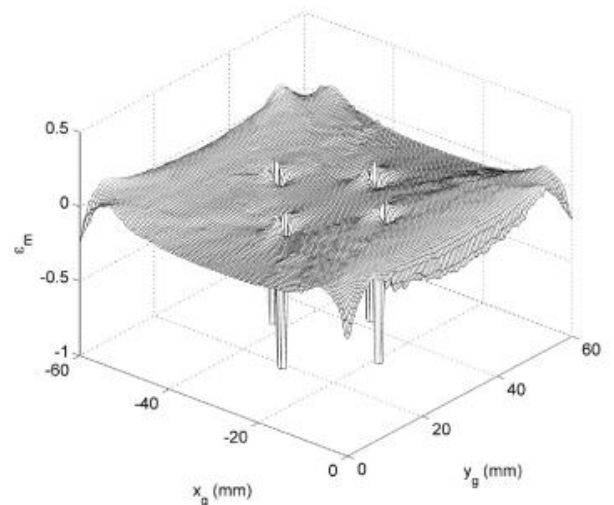

(b)

Figure 5 Surface plot showing the deviation in sample induction from the mean value for (a) case 7 having a tip width of $45 \mathrm{~mm}$, no pole air-gaps and $\mathrm{B}_{\mathrm{ca}}=1.77 \mathrm{~T}$, (b) case PAG, with tip width at $45 \mathrm{~mm}$, symmetric pole air gaps and $\mathrm{B}_{\mathrm{ca}}=1.77 \mathrm{~T}$

\section{Conclusion}

By considering the Mean rate of change criterion, $\mathrm{M}_{\mathrm{Bxy}}$, and the mean induction deviation criteria, the following conclusions can be drawn flowing from the results presented above:

i) Induction uniformity is largely unaffected by the pole laminate orientation for high induction values and where the sample air gap is larger than $1 \mathrm{~mm}$, ref. cases 3and 4 . For low induction values a parallel orientation of the pole tips will produce a more uniform field ref. cases 1 and 2

ii) For a sample air gap of $1 \mathrm{~mm}$ a Tip width of $45 \mathrm{~mm}$ will result in the best global induction uniformity at low induction values, however induction deviations for such geometry exceed those presented by the $60 \mathrm{~mm}$ case at high induction values (ref. cases 5, 6, 7, and 8). If a large sample air-gap were to be considered, than the $60 \mathrm{~mm}$ tip width provides for better uniformity ( ref. cases 1 and 11)

iii) Cases 7 and 3, confirm that a larger air gap leads to better induction uniformity, at the cost of reduced mean magnitude, with $1.77 \mathrm{~T}$ and $1.75 \mathrm{~T}$ respectively.

iv) From cases 1, 9,10, it can be seen that introducing a 45 degree side taper can help uniformity, ( ref case 1 and 10) for the case in which a $45 \mathrm{~mm}$ tip width is considered with a $3 \mathrm{~mm}$ air gap. Otherwise such a feature does not greatly enhance uniformity, (ref cases $11,12,13$ ).

v) From cases 5, 14, 15, it can be seen that the B-sensing coil aperture is critical in through-hole setups.

vi) Introducing pole air gaps reduces the mean induction value; this however, is also accompanied by a reduction in uniformity. Also it should be noted that for cases PAG, PAG_asym, corner 3, ( lying opposite to the introduced gaps), exhibits the lowest deviation from the mean induction level due to the experienced increased flux leakage as expected.

\section{References}

[1] Guo,Y., Zhu J.G., Zhong J.,LuH., Jin J.X., Measurement and Modeling of Rotational Core Losses of Soft Magnetic Materials Used in Electrical Machines: A Review. IEEE Trans. on Magnetics, 2008. 44(2).

[2] Sievert, J. D., Two-dimensional magnetic measurements - history and achievements of the workshop. Przeglad Elektrotechniczny (Electrical review), 2011. 87 (9b).

[3] Sievert, J.D., Ahlers H, Birkfeld M, et al, European intercomparison of measurements of rotational power loss in electrical sheet steel. Journal of Magnetism and Magnetic Materials, 1996. 160.

[4] Brix,W., Hempel K. A., Schreoder W, Method for the measurement of rotational power loss and related properties in electrical steel sheets. IEEE Trans. on Magnetics, 1982. 18(6).

[5] Bottauscio, O., Chiampi M, Fiorillo F, Manzin A. Space and Time Distribution of Magnetic Field in 2D Magnetizers. in 8th International Workshop on One-and Two-Dimensional Magnetic Measurement and Testing 2005. Belgium: Polish Electrotechnical review.

[6] Alatawneh, N., Pillay P. Design of a Novel test Fixture to Measure Rotational Core Losses in Machine Laminations. 2011. IEEE.

[7] Pfutzner, H., Krismanic G., Yamaguchi H., Leiss E., Chiang WC., A study on possible sources of errors of loss measurement under rotational magnetization. Przeglad Elektrotechniczny (Electrical review), 2007. 83(4).

[8] Enokizono, M., Sievert J D, Numerical Analysis of Accuracy of Roataional Magnetic Loss Measurement Apparatus. IEEE Trans. on Magnetics in Japan, 1990. 5 (9). 